Departement für Kleintiere, Abteilung für Bildgebende Diagnostik der Vetsuisse-Fakultät Universität Zürich

Leitung der Abteilung für Bildgebende Diagnostik:

Prof. Dr. med. vet. Patrick R. Kircher, PhD, Dipl. ECVDI

Arbeit unter Leitung von PD Dr. med. vet. Stefanie Ohlerth, Dipl. ECVDI

\title{
Does real-time elastography aid in differentiating canine splenic nodules?
}

\author{
Inaugural-Dissertation \\ Zur Erlangung der Doktorwürde der \\ Vetsuisse-Fakultät Universität Zürich
}

vorgelegt von

Daniela Simone Alder

Tierärztin

von Schönengrund/AR

genehmigt auf Antrag von

PD Prof. Dr. med. vet. Patrick R. Kircher, PhD, Dipl. ECVDI, Referent

Zürich 2013 


\section{Inhaltsverzeichnis}

Summary

Zusammenfassung

Introduction

Animals, Materials and Methods

Patients

Ultrasonography

Image Analysis

Statistical Analyses

Results

Discussion

References

Figures

Lebenslauf
Seite 1

Seite 2

Seite 3

Seite 4

Seite 4

Seite 5

Seite 6

Seite 7

Seite 7

Seite 9

Seite 11 


\section{Does real-time elastography aid in differentiating canine splenic nodules?}

D. Alder ${ }^{1}$, D. Bass ${ }^{2}$, M. Spörri ${ }^{3}$, P. Kircher ${ }^{2}$, S. Ohlerth ${ }^{2}$

${ }^{1}$ Clinic for Small Animal Surgery, ${ }^{2}$ Section of Diagnostic

Imaging and ${ }^{3}$ Section of Small Animal Reproduction, Vetsuisse Faculty, University of Zurich

This study was supported by Bracco Research SA, Geneva, Switzerland.

Summary

Real-time elastography is a new ultrasonographic technology for measurement of tissue elasticity. Malignant lesions in the human breast, prostate, thyroid and lymph nodes show significantly reduced elasticity. The present study investigated the use of real-time elastography in the spleen of 22 dogs ( 8 benign and 6 malignant nodules, and 8 normal spleens) and results were compared to contrast-enhanced ultrasound findings. In summary, real-time elastography was neither able to differentiate benign from malignant splenic lesions, nor normal from diseased splenic tissue. No significant associations with contrastenhanced ultrasound results were found. Real-time elastography, therefore, does not appear a useful tool for the differentiation of splenic nodules in the dog.

Keywords: spleen, dog, real-time elastography, contrast-enhanced ultrasound, ultrasound 
Hilft die Echtzeit-Elastographie bei der Differenzierung von Milzknoten des Hundes?

Zusammenfassung

Die Echtzeit-Elastographie ist eine neue Ultraschalltechnologie zur Bestimmung der Gewebeelastizität. Beim Menschen weisen maligne Knoten in der Brust, Prostata, Thyroidea und Lymphknoten eine signifikant reduzierte Elastizität auf. In der vorliegenden Studie wurde die Echtzeit-Elastographie in der Milz von 22 Hunden eingesetzt ( 8 benigne und 6 maligne Knoten, 8 normale Milzen). Es konnten weder benigne von malignen Knoten noch verändertes von normalem Milzgewebe unterschieden werden. Die Ergebnisse korrelierten nicht mit den Befunden des kontrastmittelverstärkten Ultraschalls. Daher scheint sich die Echtzeit-Elastographie nicht für die Differenzierung von Milzknoten beim Hund zu eignen.

Schlüsselwörter: Milz, Hund, Echtzeit-Elastographie, kontrastmittelverstärkte Sonographie, Ultraschall 
Introduction

Neoplastic diseases occur with high incidence in the canine spleen, and differentiation between malignant and benign changes is crucial because it influences treatment and prognosis. B-mode ultrasound is a commonly used, noninvasive and cost-effective tool in veterinary medicine to examine the canine spleen. It is considered highly sensitive for the detection of focal or diffuse lesions but its specificity is low. Moreover, splenic fine-needle aspiration has been reported to yield a correct diagnosis in only $61.3 \%$ and $51.4 \%$ of affected dogs, respectively. Histologic examination is therefore often required (Ballegeer et al., 2005; Watson et al., 2011).

Contrast-enhanced ultrasound with second-generation contrast agents represents a relatively new ultrasonographic technology for the investigation of tissue perfusion dynamics. Previous studies in dogs showed that the differentiation between malignant and benign focal splenic lesions was improved. In general, moderate to severe hypoechogenicity of a splenic nodule in comparison to normal spleen appears to be strongly suggestive of malignancy in dogs (Ohlerth et al., 2008). Characteristic vessel patterns such as feeding vessels or aberrant, tortuous intratumoral vessels have also been identified in malignant but not in benign focal splenic lesions (Taeymans and Penninck, 2011). However, marked enhancement during the vascular phases may likewise occur in benign as well as in malignant lesions. Then, contrast-enhanced ultrasound appears to be of limited value and histology is needed (Ohlerth et al., 2008).

Real-time elastography is a new ultrasonographic technology for measurement of tissue elasticity integrated in a conventional ultrasound machine with conventional probes (Ophir et al., 1991). It may be used to assess tissue elasticity with a penetration depth up to approximately $4 \mathrm{~cm}$. Images are generated by slight compression and decompression of tissue, which is manually induced by the investigator using an abdominal ultrasound probe. Tissue compression results in deformation within the tissue. Harder, stiffer tissue will be less deformed e.g. less elastic than softer, more elastic tissue (Garra, 2011). Real-time elastography computes the so-called strain (compressibility property of materials) by determination of local displacements between two consecutive images. After processing the radiofrequency ultrasound data, the elastogram is simultaneously displayed with conventional B-mode images (Ophir et al., 1991). The stiffness of the lesion is displayed in different, freely selectable colors. In focal lesions of the human breast (Barr, 2012), prostate (Pozzi et al., 2012), thyroid (Wang et al., 2013) and lymph nodes (Teng et al., 2012), it has been shown that malignant nodules are significantly stiffer than surrounding 
normal tissue. So far, one report in veterinary medicine describes real-time elastography as a feasible and repeatable method for the evaluation of the elasticity of the normal equine tendons (Seiler, 2011).

The objectives of the present study were 1) to assess the feasibility of real-time elastography for the evaluation of the elasticity of the canine spleen, 2) to verify that benign focal splenic lesions would present higher elasticity than malignant nodules, and 3) elastographic appearance of splenic nodules was compared to contrast-enhanced ultrasound findings to investigate if real-time elastography would help to differentiate lesions with marked enhancement, which according to the literature, may likewise represent benign as well as malignant lesions.

Animals, Material and Methods

Patients

A prospective study was conducted in dogs with single focal splenic lesions diagnosed during routine abdominal ultrasonography at the Section of Diagnostic Imaging at the University of Zurich between May 2011 and April 2012. Twenty-two dogs were included in the study: 4 Labrador Retrievers, 2 Golden Retrievers, and one each of various breeds. Age ranged from 1 to 13 years (mean 8.8 years; SD 3.6 years), and body weight ranged from 2 to $43 \mathrm{~kg}$ (mean $24.64 \mathrm{~kg}$; SD $10.7 \mathrm{~kg}$ ). Nine dogs were male and 13 were female. Dogs were included in the study if real-time elastography was performed and diagnostic ultrasound-guided aspirates or histopathologic samples were taken within the same day during surgery or necropsy. Lesions had to be located in a depth of less than $4 \mathrm{~cm}$. Healthy dogs with normal spleens or dogs presented for clinical signs unrelated to the spleen were included as a control group. Cytology or histology was not available in these animals. Owner consent was obtained. The study was approved by the Animal Ethics Council of the Canton of Zürich.

\section{Ultrasonography}

During the ultrasonographic examination, 16 dogs were awake and kept in lateral recumbency with manual restraint only. Six dogs were sedated/premedicated with Butorphanol (Morphasol, 0.2mg/kg) plus Midazolam (Dormicum, 0.2mg/kg) IV, Fentanyl (Sintenyl, 5-10 $\mu \mathrm{g} / \mathrm{kg}$ ) plus Midazolam (Dormicum, $0.25 \mathrm{mg} / \mathrm{kg}$ ) IV, or Methadon (Methadon Streuli, 0.2mg/kg) or Butorphanol (Morphasol, 0.2mg/kg) plus Acepromazin (Prequillan, $10 \mu \mathrm{g} / \mathrm{kg}$ ) IM. Two dogs underwent subsequent general anesthesia with 
Propofol (Propofol 1\% MCT Fresenius) given IV to effect. All examinations were performed with the same ultrasound unit (iU22, Philips, Zurich, Schweiz). The area of examination was clipped and lubricated with gel. The following criteria were assessed in the spleen with B-mode: size of the lesion, echogenicity in comparison to the surrounding normal splenic tissue, heterogeneity and presence of cavernous areas. Splenic tissue was considered normal if the contours were smooth and regular, and the parenchyma appeared uniform, finely textured and more echogenic than the liver and the cortex of the left kidney.

For real-time elastography, a L12-5 MHz linear array transducer was used in combination with a real-time elastography module. Slight compression of the spleen was manually induced with the probe. The compression feedback bar displaying the amount of tissue deformation in the ultrasound image had to be of a green color indicating an adequate amount of pressure. Tissue deformation was considered fair if the compression feedback bar was seen in the lower third of the green bar, and good or excellent if it was in the middle third or in the upper third of the green bar, respectively. The selected color scheme displayed soft, high strain areas in red, whereas intermediate, average strain areas were coded with a green color and hard, no strain areas with a blue color. At least one cine clip of a minimum of 20 seconds was obtained.

Contrast-enhanced ultrasound was performed subsequently to real-time elastography. A 3$9 \mathrm{MHz}$ linear probe or a 2-5 MHz broadband curvilinear probe and pulse inversion harmonic imaging were used with standardized machine presets. While the probe remained in the same position, the contrast medium (SonoVue, $0.03 \mathrm{ml} / \mathrm{kg}$ ) was administered IV through the cephalic vein as a rapid bolus followed by a rapid bolus of $5 \mathrm{ml}$ saline. With the onset of injection, images were acquired for approximately 180 seconds and stored as Dicom-files with the extended loop function of the ultrasound machine.

Image analysis

Elastography: Two authors (DA, SO) evaluated the images together. The 5-point scoring system described for human breast lesions (Zhi et al., 2010) was modified and applied. A score of 1 was defined as normal and even strain (green color) in the lesion, equal to the surrounding tissue, respectively. A score of 2 represented normal strain in $\geq 75 \%$ of the lesion with some areas of less strain in the lesion (mosaic pattern, green and little blue) and normal strain in in the surrounding tissue. A score of 3 described a heavily mixed pattern of less, normal or increased strain in the lesion, but normal strain in the surrounding area. 
A score of 4 represented largely absent strain in the lesion (blue) but normal strain in the surrounding tissue (green). A score of 5 indicated no strain in the lesion and surrounding tissue. A score of 1 to 3 was considered benign whereas a score of 4 or 5 was categorized as malignant.

The semiquantitative strain ratio was also applied in the present study. Two regions of interest, drawn as large as possible, were manually selected in every image in the lesion and the adjacent normal spleen, respectively. Both regions of interest were drawn at a similar tissue depth avoiding inclusion of larger vessels or cavitary areas. With dedicated software (QLab Version 8.1, Philips Ultrasound, Bothell, WA, USA) a ratio was calculated between the average strain of normal tissue and the lesion. For both, the elasticity score and the strain ratio, a minimum of 3 image sequences with $\geq 3$ consecutive images of adequate quality were analyzed to calculate a mean.

Contrast harmonic imaging: The enhancement pattern (homogeneous, heterogeneous), presence of cavernous areas (yes/no), ring enhancement (yes/no), presence of feeding vessels during the early or late vascular phase (yes/no), lesion enhancement compared to normal spleen (hypo-, iso-, or hyperechoic) during the early, peak or late vascular phase were evaluated. Hypoechogenicity was subclassified as mild (marked enhancement of lesion with marginal hypoechogenicity in comparison to normal spleen), moderate (little enhancement of lesion) or extensive (no enhancement).

Statistical analyses

Because groups were small, nonparametric statistical tests were used. To assess the association of the elasticity score and the strain ratio with the continuous variables body weight and age Spearman correlation coefficients were calculated; for the categorical variables sex and anesthesia, the Mann-Whitney-U test was used. The Mann-Whitney-U test was also used a) to assess the association between mean elasticity score and strain ratio of lesions with malignancy, b) to compare mean elasticity score and strain ratio between normal spleen surrounding benign and malignant lesions, and normal spleens of control animals, and, c) to assess the associations between mean elasticity score and strain ratio of lesions with the degree of hypoechogenicity during the early, peak and late vascular phase. The Wilcoxon-signed-rank test was used to compare mean elasticity score of lesions and normal spleen surrounding the nodules. All statistical analyses were performed with commercially available software (IBM SPSS Statistics Version 19, Zurich, Switzerland). Level of significance was $\mathrm{p}<0.05$. 
Results

No significant association was found between the continuous variables age and body weight and the elasticity variables, respectively. There was neither a significant difference between male and female dogs, nor sedated and non-sedated animals.

In all diseased spleens, ultrasound-guided fine needle aspirates (11) or histology (3) was available. Eight lesions were considered benign, 6 nodules were malignant (Table 1).

Three lesions were hypoechoic and 11 nodules were of mixed echogenicity. Cavitary areas were diagnosed in 7 lesions, independent of their cytological diagnosis (i.e., benign or malignant).

Quality of elastographic images was good to excellent in $19(86.3 \%)$ cases, the remaining 3 cases classified as fair. Mean elasticity score did not significantly differ between benign and malignant lesions $(\mathrm{p}=0.3)$, between normal spleen tissue surrounding benign or malignant nodules and healthy spleens of the control group $(p=0.6)$, and between all lesions and normal surrounding spleen tissue $(p=0.6)$ (Fig 1). Likewise, mean strain ratio did not significantly differ between benign and malignant lesions $(\mathrm{p}=0.9)$.

Contrast-enhanced ultrasound was performed in 10 ( 5 benign, 5 malignant) of the 14 nodules. The overall quality of the contrast harmonic imaging was good to excellent in all but one examination with fair quality. The pattern of enhancement was heterogeneous in 5 lesions. Ring enhancement was found in 2 nodules. Tortuous feeding vessels during the early and late phase were identified in 1 benign and 3 malignant lesions. Degree of enhancement of the lesions in comparison to normal spleen is shown in Table 1. If lesions were categorized in two groups for every vascular phase (extensive to moderate hypoechogenicity versus mild hypoechogenicity to hyperechogenicity), mean elasticity score and strain ratio did not significantly differ between the two groups for the early, peak or late vascular phase $(\mathrm{p}=0.14-0.9)$.

\section{Discussion}

In various human organs, malignancies were shown to be significantly stiffer than benign lesions or surrounding normal tissue (Garra, 2011). Because of the limitations of B-mode, real-time elastography could represent an easy accomplishable and non-invasive tool to differentiate benign from malignant splenic lesions in the dog, in particular if combined with contrast-enhanced ultrasound. In the present study, real-time elastography appeared feasible but no additional diagnostic value was found. Mean elasticity scores and strain ratios were very similar for all canine splenic tissues and ranged between 3.4 and 3.8 and 
0.9 and 1.32, respectively. Compared to the human classification, the present elasticity scores indicate moderate stiffness in all splenic tissues, independent of the presence and type of disease. The calculated mean strain ratio was around 1, indicating similar moderate stiffness of normal, benign, and malignant splenic tissue. For comparison, mean strain ratios in benign and malignant human breast lesions were 1.83 and 8.42 , respectively, with a cutoff point of 3.05 and an accuracy of $91.4 \%$ (Zhi et al., 2010). Although the elasticity property of spleen tissue has not been described in detail in the literature, a few theories may explain our findings to a certain degree. First, the normal spleen represents a highly vascularized organ storing a large quantity of erythrocytes. Amount of stored blood in and perfusion of the canine spleen during ultrasonography may vary widely within and between individuals. Moreover, in sedated or anesthetized animals, splenic congestion may occur depending on the drugs used (O'Brien et al., 2004). Both, nonneoplastic as well as neoplastic lesions, may contain a large quantity of vessels or cavernous areas. Physically, fluids cannot be compressed and are stiff. In humans, an increased blood flow to the spleen increased significantly the stiffness of the organ (Hirooka et al., 2011). However, there are no elastographic studies in humans investigating splenic lesions.

In recent years, cancer research has shown that excessive remodeling of the extracellular matrix increases the stiffness of tumor stroma. The increased stiffness is mainly a result of increased deposition of type I collagen and fibronectin. The deposit is forming a dense fibrous band around the tumor and is generally associated only with malignant tumors, such as human breast, liver, and head and neck cancer (Levental et al., 2009; Cox et al., 2011). Studies in the normal and diseased spleen investigating the implication of the extracellular matrix are lacking.

Although real-time elastography was easy to perform in the present study, animal-specific factors such as increased abdominal wall tension may have played a role decreasing the overall elasticity of the spleen and/or nodules.

A limitation of the present study may represent the use of real-time elastography as an elastographic method since it only allows subjective and semiquantitative assessment. In human medicine, newer techniques allowing a quantitative approach (measurements in Pascal) are more sensitive and reliable (Nightingale, 2011).

The above-mentioned factors and the small number of examined animals may have contributed to the moderate and similar elasticity measurements in both, normal spleen tissue as well as benign or malignant lesions. 
In conclusion, real-time elastography was not found a useful tool for the differentiation of splenic nodules in the dog. However, newer techniques allowing a quantitative approach to measure tissue stiffness should be investigated in a larger cohort of dogs in the future. Studies on the microenvironment of splenic tumors, in particular the behavior of tumor stroma in the spleen, are pending.

\section{References}

Ballegeer E., Forrest L., Dickinson R., Schutten M., Delaney F., Young K.: Correlation of ultrasonographic appearance of lesions and cytologic and histologic diagnoses in splenic aspirates from dogs and cats: 32 cases (2002-2005). J. Am. Vet. Med. Assoc. 2007, 230: 690-696.

Barr R.: Sonographic breast elastography: a primer. J. Ultrasound Med. 2012, 31: 773-783. Cox T., Erler J.: Remodeling and homeostasis of the extracellular matrix: implications for fibrotic diseases and cancer. Dis. Model Mech. 2011, 4: 165-178.

Evans A., Whelehan P., Thomson K., McLean D., Brauer K., Purdie C., Baker L., Jordan L., Rauchhaus P., Thompson A.: Invasive breast cancer: relationship between shear-wave elastographic findings and histologic prognostic factors. Radiology 2012, 263: 673-677. Garra B.: Elastography: current status, future prospects, and making it work for you. Ultrasound Q. 2011, 27: 177-186.

Hirooka M., Ochi H., Koizumi Y., Abe M., Ikeda Y., Matsuura B., Hiasa Y., Onji M.: Splenic elasticity measured with real-time tissue elastography is a marker of portal hypertension. Radiology 2011, 261: 960-968.

Itoh A., Ueno E., Tohno E.: Breast disease: clinical application of US elastography for diagnosis. Radiology 2006, 239: 341-350.

Levental K., Yu H., Kass L., Lakins J., Egeblad M., Erler J., Fong S., Csiszar K., Giaccia A., Weninger W., Yamauchi M., Gasser D., Weaver V.: Matrix crosslinking forces tumor progression by enhancing integrin signaling. Cell 2009, 139: 891-906.

Nightingale K.: Acoustic Radiation Force Impulse (ARFI) Imaging: a review. Curr. Med. Imaging Rev. 2011, 7: 328-339.

O’Brien R., Waller K., Osgood T.: Sonographic features of drug-induced splenic congestion. Vet. Radiol. Ultrasound 2004, 45: 225-227.

Ohlerth S., Dennler M., Rüefli E., Hauser B., Poirier V., Siebeck N., Roos M., Kaser-Hotz B.: Contrast harmonic imaging characterization of canine splenic lesions. J. Vet. Intern. Med. 2008, 22: 1095-1102. 
Ophir J., Céspedes I., Ponnekanti H., Yazdi Y., Li X.: Elastography: a quantitative method for imaging the elasticity of biological tissues. Ultrason. Imaging 1991, 13: 111-134. Pozzi E., Mantica G., Gastaldi C., Berardinelli M., Choussos D., Bianchi C., Roggia A.: The role of the elastography in the diagnosis of prostate cancer: a retrospective study on 460 patients. Arch. Ital. Urol. Androl. 2012, 84: 151-154.

Sarvazyan A., Hall T., Urban M., Fatemi M., Aglyamov S., Garra B.: An overview of elastography - an emerging branch of medical imaging. Curr. Med. Imaging Rev. 2011, 7: $255-282$.

Seiler G., Lustgarten M., Redding W.: Elastographic evaluation of normal tendons and ligaments of the equine distal forelimb. Vet. Radiol. Ultrasound 2011, 52: 691.

Taeymans O., Pennick D.: Contrast enhanced sonographic assessment of feeding vessels as a discriminator between malignant vs. benign focal splenic lesions. Vet. Radiol.

Ultrasound 2011, 52: 457-461.

Teng, D., Wang H., Lin Y., Sui G., Guo F., Sun L.: Value of ultrasound elastography in assessment of enlarged cervical lymph nodes. Asian Pac. J. Cancer Prev. 2012, 13: 20812085.

Wang H., Brylka D., Sun L., Lin Y., Sui G., Gao J.: Comparison of strain ratio with elastography score system in differentiating malignant from benign thyroid nodules. Clin. Imaging 2013, 37: 50-55.

Watson A., Pennick D., Knoll J., Keating J., Sutherland-Smith J.: Safety and correlation of test results of combined ultrasound-guided fine-needle aspiration and needle core biopsy of the canine spleen. Vet. Radiol. Ultrasound 2011, 52: 317-322.

Zhi H., Xiao X., Yang H., Ou B., Wen Y., Luo B.: Ultrasonic elastography in breast cancer diagnosis: strain ratio vs. 5-point scale. Acad. Radiol. 2010, 17: 1227-1233. 

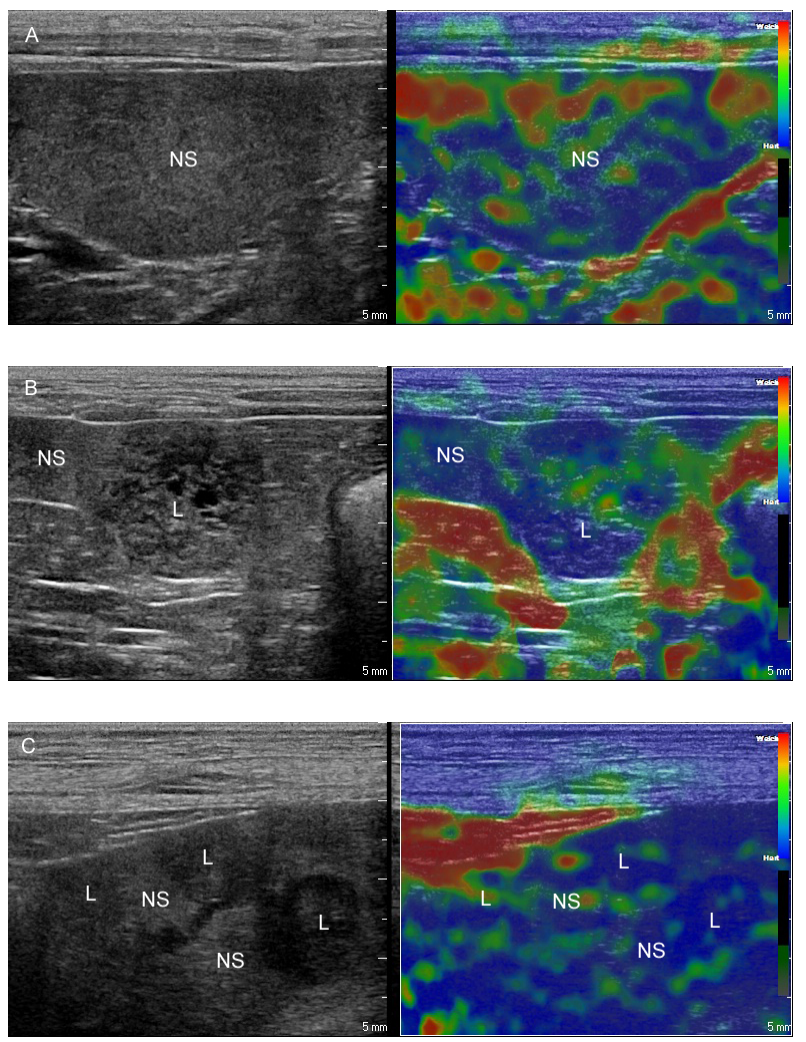

Figure 1:

B-mode ultrasound images (left) and ultrasonic elastographic images (right) in a side by side display of (A) the normal spleen of dog 15, (B) a hyperplastic nodule in the spleen of $\operatorname{dog} 14$, and (C) metastatic carcinoma to the spleen of dog 5 . The green compression feedback bar is seen on the bottom right. The selected elastographic color scheme displays soft, high strain areas in red, whereas intermediate, average strain areas are coded with a green color and hard, no strain areas with a blue color. Note that elasticity does not differ between a benign or malignant lesion and the normal surrounding spleen $(B, C)$ and that the benign (B) and the malignant $(\mathrm{C})$ nodule show a similar elasticity score (mean: 3 and 3.67, respectively). The normal spleen (A) appears softer (less blue color); however, elasticity score is also 3. L: lesion, NS: normal spleen. 
Table 1: Mean elasticity score, strain ratio, B-mode and contrast-enhanced ultrasound (CEUS) findings and final diagnosis of the investigated splenic nodules and the healthy control spleens

(N.A.: not assessed; CEUS: lesion enhancement in comparison to normal spleen: 1: hyperechoic, 2: isoechoic, 3: mildly hypoechoic, 4: moderately hypoechoic, 5: no enhancement)

\begin{tabular}{|c|c|c|c|c|c|c|c|}
\hline Dog & Diagnosis & $\begin{array}{c}\text { CEUS - } \\
\text { early vascular } \\
\text { phase } \\
\end{array}$ & $\begin{array}{c}\text { CEUS - } \\
\text { peak }\end{array}$ & $\begin{array}{c}\text { CEUS - } \\
\text { late vascular } \\
\text { phase } \\
\end{array}$ & $\begin{array}{c}\text { Elasticity score of } \\
\text { lesion }\end{array}$ & $\begin{array}{l}\text { Elasticity score of } \\
\text { surrounding normal } \\
\text { spleen }\end{array}$ & Strain ratio \\
\hline 1 & Hemangiosarcoma & 4 & 4 & 4 & 3 & 4 & 0.42 \\
\hline 2 & Hemangiosarcoma & 4 & 4 & 4 & 4 & 4 & 0.78 \\
\hline 3 & Histiocytic sarcoma & 4 & 4 & 4 & 3.67 & 3.33 & 1.26 \\
\hline 4 & Metastatic carcinoma & N.A. & N.A. & N.A. & 5 & 3 & 3.9 \\
\hline 5 & Metastatic carcinoma & 1 & 4 & 2 & 3.67 & 3.67 & 0.93 \\
\hline 6 & Malignant round cell neoplasia & 3 & 3 & 3 & 4 & 4.67 & 0.63 \\
\hline 7 & Hematoma & N.A. & N.A. & N.A. & 2.33 & 3.33 & 0.54 \\
\hline 8 & Infarct & 4 & 4 & 5 & 4 & 4 & 1.07 \\
\hline 9 & Extramedullary erythropoesis & 5 & 5 & 5 & 3 & 3.33 & 1 \\
\hline 10 & Extramedullary erythropoesis & 4 & 4 & 4 & 4 & 4 & 0.95 \\
\hline 11 & Extramedullary erythropoesis & N.A. & N.A. & N.A. & 4.33 & 4.33 & 1.22 \\
\hline 12 & Nodular hyperplasia & 2 & 3 & 4 & 2.67 & 3.33 & 0.67 \\
\hline 13 & Nodular hyperplasia & N.A. & N.A. & N.A. & 3.67 & 4 & 0.84 \\
\hline 14 & Nodular hyperplasia & 3 & 3 & 3 & 3 & 2.33 & 0.91 \\
\hline 15 & Normal spleen (control group) & \multirow{8}{*}{\multicolumn{3}{|c|}{$\begin{array}{l}\text { N.A. } \\
\text { N.A. } \\
\text { N.A. } \\
\text { N.A. } \\
\text { N.A. } \\
\text { N.A. } \\
\text { N.A. } \\
\text { N.A. }\end{array}$}} & - & 3 & - \\
\hline 16 & Normal spleen (control group) & & & & - & 4 & - \\
\hline 17 & Normal spleen (control group) & & & & - & 4 & - \\
\hline 18 & Normal spleen (control group) & & & & - & 3 & - \\
\hline 19 & Normal spleen (control group) & & & & - & 4 & - \\
\hline 20 & Normal spleen (control group) & & & & - & 3 & - \\
\hline 21 & Normal spleen (control group) & & & & - & 3 & - \\
\hline 22 & Normal spleen (control group) & & & & - & 3.67 & - \\
\hline
\end{tabular}




\section{Curriculum Vitae}

Name, Vornamen

Geburtsdatum

Geburtsort

Nationalität

Heimatort

$06 / 1997-09 / 2001$

03.09.2001

$10 / 2001-09 / 2007$

14.09.2007

$03 / 2011-04 / 2012$

$01 / 2008-12 / 2009$

$01 / 2010-04 / 2011$

$04 / 2011-04 / 2012$

05/2012 - jetzt
Alder, Daniela Simone

06.10 .1982

Effretikon/ZH

Schweizerin

Schönengrund/AR

Kantonsschule Trogen/AR

Matura, Kantonsschule Trogen/AR, Schweiz

Veterinärmedizin-Studium, Universität Bern, Schweiz

Staatsexamen, Universität Bern, Schweiz

Anfertigung der Dissertation unter der Leitung von PD Dr. med. vet. Stefanie Ohlerth, Dipl. ECVDI am Departement für Kleintiere, Abteilung Bildgebende Diagnostik an der Vetsuisse-Fakultät Universität Zürich Leitung Abteilung für Bildgebende Diagnostik:

Prof. Dr. med. vet. Patrick R. Kircher, PhD, Dipl. ECVDI

Internship Tierklinik Birkenfeld

Dr. Dr. hc H.-J. Koch, Dipl. ECVD, 55765 Birkenfeld, Deutschland

Assistentin Tierklinik Birkenfeld

Dr. Dr. hc H.-J. Koch, Dipl. ECVD, 55765 Birkenfeld, Deutschland

Doktorandin an der Abteilung für Bildgebende Diagnostik, Departement für Kleintiere, Universität Zürich

Assistentin an der Klinik für Kleintierchirurgie, Abteilung für Neurologie, Universität Zürich 